\title{
DEGRO practical guidelines for radiotherapy of breast cancer VI: therapy of locoregional breast cancer recurrences
}

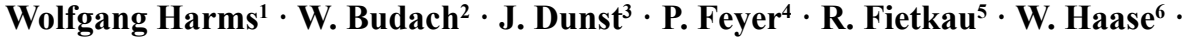 \\ D. Krug ${ }^{7}$ M. D. Piroth ${ }^{8}$ - M.-L. Sautter-Bihl ${ }^{9}$ F. Sedlmayer ${ }^{10} \cdot$ R. Souchon ${ }^{11}$ \\ F. Wenz ${ }^{12} \cdot$ R. Sauer ${ }^{5}$ Breast Cancer Expert Panel of the German Society of \\ Radiation Oncology (DEGRO)
}

Received: 19 December 2015 / Accepted: 22 December 2015 / Published online: 1 March 2016

(C) The Author(s) 2016. This article is published with open access at Springerlink.com

\begin{abstract}
Objective To update the practical guidelines for radiotherapy of patients with locoregional breast cancer recurrences based on the current German interdisciplinary S3 guidelines 2012.

Methods A comprehensive survey of the literature using the search phrases "locoregional breast cancer recurrence", "chest wall recurrence", "local recurrence", "regional recurrence", and "breast cancer" was performed, using the limits "clinical trials", "randomized trials", "meta-analysis", "systematic review", and "guidelines".
\end{abstract}

Prof. Dr. med. Wolfgang Harms

wolfgang.harms@claraspital.ch

1 Abteilung für Radioonkologie, St. Claraspital, Kleinriehenstrasse 30, 4016 Basel, Switzerland

2 Heinrich-Heine-University, Duesseldorf, Germany

3 University Hospital Schleswig-Holstein, Kiel, Germany

4 Vivantes Hospital Neukoelln, Berlin, Germany

5 University Hospital Erlangen, Erlangen, Germany

6 Formerly St.-Vincentius-Hospital, Karlsruhe, Germany

7 University Hospital Heidelberg, Heidelberg, Germany

8 HELIOS-Hospital Wuppertal, Witten/Herdecke University, Wuppertal, Germany

9 Municipal Hospital, Karlsruhe, Germany

10 Paracelsus Medical University Hospital, Salzburg, Austria

11 Formerly University Hospital Tuebingen, Tuebingen, Germany

12 University Medical Center Mannheim, Medical Faculty Mannheim, University of Heidelberg, Mannheim, Germany
Conclusions Patients with isolated in-breast or regional breast cancer recurrences should be treated with curative intent. Mastectomy is the standard of care for patients with ipsilateral breast tumor recurrence. In a subset of patients, a second breast conservation followed by partial breast irradiation (PBI) is an appropriate alternative to mastectomy. If a second breast conservation is performed, additional irradiation should be mandatory. The largest reirradiation experience base exists for multicatheter brachytherapy; however, prospective clinical trials are needed to clearly define selection criteria, long-term local control, and toxicity.

Following primary mastectomy, patients with resectable locoregional breast cancer recurrences should receive multimodality therapy including systemic therapy, surgery, and radiation $+/-$ hyperthermia. This approach results in high local control rates and long-term survival is achieved in a subset of patients. In radiation-naive patients with unresectable locoregional recurrences, radiation therapy is mandatory. In previously irradiated patients with a high risk of a second local recurrence after surgical resection or in patients with unresectable recurrences, reirradiation should be strongly considered. Indication and dose concepts depend on the time interval to first radiotherapy, presence of late radiation effects, and concurrent or sequential systemic treatment. Combination with hyperthermia can further improve tumor control.

In patients with isolated axillary or supraclavicular recurrence, durable disease control is best achieved with multimodality therapy including surgery and radiotherapy. Radiation therapy significantly improves local control and should be applied whenever feasible.

Keywords Chest wall recurrence breast cancer . Axillary recurrence breast cancer .

Supraclavicular recurrence breast cancer - Mastectomy · Reirradiation 


\section{DEGRO-Leitlinien für die Strahlentherapie des Mammakarzinoms VI: Therapie lokoregionaler Mammakarzinomrezidive}

\section{Zusammenfassung}

Ziel Aktualisierung der Strahlentherapieleitlinien bei Patienten mit lokoregionalen Mammakarzinomrezidiven, basierend auf der aktuellen S3-Leitlinie.

Methoden Es erfolgte eine umfassende Recherche der wissenschaftlichen Literatur mit den Suchbegriffen: „lokoregionales Mammakarzinomrezidiv“, „Thoraxwandrezidiv“, „Lokalrezidiv“, „regionales Rezidiv“ und „Mammakarzinom“, eingeschränkt durch die Begriffe „klinische Studie“, „randomisierte Studie“, „Metaanalyse“, „systematischer Review" und „Leitlinie“.

Schlussfolgerungen Patienten mit isolierten In-Brust- oder regionalen Rezidiven sollten mit kurativer Intention behandelt werden. Bei Patienten mit einem ipsilateralen In-BrustRezidiv ist eine Mastektomie die Standardbehandlung. Bei einem Teil der Patienten ist eine erneute Brusterhaltung mit anschließender Teilbrustbestrahlung eine angemessene Alternative zur Mastektomie. Nach erneuter Brusterhaltung sollte eine Bestrahlung obligat durchgeführt werden. Die größten Erfahrungen zur Rebestrahlung existieren für die Multikatheter-Brachytherapie. Dennoch sind prospektive Studien notwendig, um Selektionskriterien sowie Langzeittoxizität und -kontrollraten genauer zu bestimmen.

Patienten mit resektablen lokoregionalen Mammakarzinomrezidiven nach primärer Mastektomie sollten mit einem multimodalen Therapiekonzept mit kompletter Resektion, systemischer Therapie und Bestrahlung +/- Hyperthermie behandelt werden. Hierdurch können hohe lokale Kontrollraten und in einem Teil der Patienten lange Überlebenszeiten erreicht werden. Eine Strahlentherapie sollte obligat bei bisher nicht bestrahlten Patienten mit inoperablen lokoregionalen Rezidiven durchgeführt werden. Bei vorbestrahlten Patienten mit einem hohen Rezidivrisiko nach chirurgischer Resektion oder einem inoperablen Rezidiv sollte eine Rebestrahlung dringend in Erwägung gezogen werden. Indikationsstellung und Dosiskonzepte sind vom Intervall zur ersten Bestrahlung, der Präsenz und dem Ausmaß später Strahlenreaktionen sowie von parallelen/sequenziellen systemischen Therapien abhängig. Eine Kombination mit einer zusätzlichen Hyperthermie kann die Tumorkontrolle weiter verbessern.

Bei Patienten mit isolierten axillären oder supraklavikulären Rezidiven kann eine dauerhafte Krankheitskontrolle am besten mit einem multimodalen Behandlungskonzept bestehend aus Chirurgie und Radiotherapie erreicht werden. Eine Strahlentherapie sollte, wann immer möglich, durchgeführt werden, da sie zu einer signifikanten Verbesserung der lokalen Kontrolle führt.
Schlüsselwörter Brustwandrezidiv Mammakarzinom • Axilläres Rezidiv Mammakarzinom · Supraklavikuläres Rezidiv Mammakarzinom · Mastektomie $\cdot$ Rebestrahlung

\section{Introduction}

Treatment of locally recurrent breast cancer remains an interdisciplinary challenge, since treatment options are limited or at least restricted due to previous treatments. Data from large randomized trials have demonstrated that locoregional recurrences occur in approximately $5-15 \%$ of patients, despite them having received adjuvant radiotherapy after primary mastectomy or breast-conserving surgery (BCS; [1-4]). The most common site of recurrence after adjuvant radiotherapy is the ipsilateral breast or chest wall, comprising $60-95 \%$ of all locoregional events [5-7]. Locoregional recurrences are typically associated with an increased risk of concurrent or subsequent systemic relapses [8, 9]. Particularly early recurrences within the first 2 years after primary treatment seem to have a worse prognosis [9]. As previous guidelines from the German Society of Radiation Oncology (DEGRO) expert panel [10-12] focused on primary treatment of breast cancer, the current publication addresses radiotherapeutic options for locoregional recurrences.

\section{Therapy of ipsilateral breast tumor recurrence}

\section{Statement of theGerman S3 Guidelines 2012 [13]: Statement recurrence 1: Local (in-breast) recurrence}

a. In patients with invasive or noninvasive in-breast recurrences, optimal local tumor control is achieved with a secondary mastectomy.

b. In patients with ductal carcinoma in situ or invasive breast cancer with a long recurrence-free interval and no skin infiltration, a second breast conservation can be considered.

c. In the case of a second breast conservation, the possibility of reirradiation (partial breast irradiation, PBI) should be evaluated.

d. In the case of a second breast conservation, the patient should be informed about an increased risk of subsequent in-breast recurrence.

BCS followed by adjuvant radiotherapy has become the standard of care for the majority of breast cancer patients. Ipsilateral breast tumor recurrence (IBTR) is diagnosed in approximately $5-10 \%$ of patients at 10 years after breastconserving therapy (BCT; [10, 14-17]). International guidelines recommend mastectomy as standard treatment for IBTR after BCT $[13,18]$. Salvage mastectomy results 
in locoregional control rates of $69-98 \%$ and 5 -year survival rates of 53-85\% $[19,20]$. Nevertheless, this approach is not founded on solid data demonstrating a clear advantage of radical surgery over a second attempt at BCT for all IBTR patients [21]. There are no published or ongoing prospective studies comparing mastectomy to repeat BCS in patients with IBTR. Published data are limited and most series reporting on a second conservative approach, with or without the addition of adjuvant radiotherapy, are singleinstitution retrospective studies. The Radiation Therapy Oncology Group (RTOG) introduced a phase II prospective trial of repeat $\mathrm{BCS}$ adding $3 \mathrm{D}$ conformal partial breast reirradiation for local recurrence in 2010 [22]. Additionally, mutilating rescue surgery causes patients enormous emotional and physical distress [23]. Furthermore, the currently implemented close follow-up routine has led to detection of IBTR at early stages technically amenable to a second breast conserving approach. Thus, a subgroup of patients remains to be defined who can be safely treated with a second breast conserving approach without oncologic compromises. Unfortunately, no prospective data have been published so far.

\section{Definition of selection criteria for a second BCS}

Veronesi et al. suggested that patients with IBTR constitute a heterogeneous group, with true tumor recurrences and new primary tumors [24]. In a large retrospective study on 1410 patients, Gujral et al. [25] reported a cumulative incidence rate of new primaries after whole-breast irradiation of $0.8,2$, and $3.5 \%$ at 5,10 , and 15 years respectively. The authors concluded that whole-breast irradiation approximately halves the rate of new primaries. Smith et al. [26] reported a significantly improved 10 -year overall survival (OS) in patients with new primaries (75\%) compared to patients with true recurrences $(55 \%)$ in a retrospective study on 136 patients with IBTR as the first site of failure. This question has been addressed in several studies attempting to differentiate between true recurrences and new primaries [26-29], from which the following conclusions can be derived: the majority of IBTR are true recurrences, which tend to occur earlier and in the same quadrant as the initial tumor, metastasize earlier and more often, and have a shorter overall and disease-free survival (DFS) than new primaries. Further retrospective studies [30-32] evaluating IBTR showed that there are subgroups of patients with improved rates of OS, DFS, and second local recurrence. Based on these data, the DEGRO expert panel suggests possible selection criteria for patients who may be candidates for a second breast-conserving approach (Table 1). However, repeat BCS alone is associated with increased local failure rates ranging between 19 and $38 \%$ (Table 2; [33]). Recent studies showed promising OS rates in selected patients treated with second
The DEGRO expert panel suggests the following selection criteria for a second breast conserving approach

Table 1 Possible selection criteria for patients with ipsilateral breast tumor recurrence who may be candidates for a second breast-conserving approach

Isolated ipsilateral breast tumor recurrence

Limited size $(<2-3 \mathrm{~cm})$

Unifocal disease on ultrasound, mammography, and MRI

Age $\geq 50$ years

Long interval between primary treatment and recurrence ( $\geq 48$ months)

Patient preference for a second breast conservation followed by radiotherapy

A second breast conservation is technically feasible and will result in acceptable cosmetic results

Table 2 Outcomes of patients treated with repeat breast conserving surgery alone following ipsilateral breast tumor recurrence

\begin{tabular}{lllll}
\hline Study/year & $\begin{array}{l}\text { Number of } \\
\text { Patients }\end{array}$ & $\begin{array}{l}\text { Median } \\
\text { follow-up } \\
\text { (months) }\end{array}$ & $\begin{array}{l}\text { Local } \\
\text { recur- } \\
\text { rence } \\
\text { rate (\%) }\end{array}$ & $\begin{array}{l}\text { 5-year } \\
\text { overall } \\
\text { survival } \\
(\%)\end{array}$ \\
\hline Kurtz [43] 1989 & 55 & 51 & 32 & NR \\
Abner [44] 1993 & 16 & 39 & 31 & 81 \\
Salvadori [45] & 57 & 73 & 19 & 85 \\
1999 & & & & \\
Voogd [46] 1999 & 16 & 52 & 38 & NR \\
Ishitobi [47] 2011 & 78 & 40 & 21 & NR \\
Gentilini [48] & 161 & 81 & 29 & 84 \\
2012 & & & & \\
\hline NR not reported & & & &
\end{tabular}

conservative surgery followed by partial-breast irradiation (PBI; [34, 35]). The following survey provides an overview of different radiation techniques applied for reirradiation after BCS for IBTR (Table 3).

\section{Brachytherapy after BCS for IBTR}

The most solid evidence for reirradiation of IBTR exists for brachytherapy (BT). The Groupe Européen de Curiethérapie and the European Society for Radiotherapy \& Oncology (GEC-ESTRO) working group reported on a retrospective collaborative analysis of 217 IBRT patients treated between 2000 and 2009 with multicatheter BT in eight European institutions [35]. The median total doses delivered through low dose rate (LDR) and pulsed dose rate (PDR) BT were 46 Gy (range 30-55 Gy) and 50.4 Gy (range 49-50 Gy), respectively, and 32 Gy (range 22-36 Gy; equivalent dose in 2-Gy fractions: $43 \mathrm{~Gy}_{4}$ ) in 5-10 fractions (median 8 fractions) fractions (twice daily) for high dose rate (HDR) BT. With a median follow-up of 3.9 years (1.110.3 years) after IBTR retreatment, the 5- and 10-year actuarial second local recurrence rates were $5.6 \%(1.5-9.5 \%)$ and $7.2 \%(2.1-12.1 \%)$, respectively. The grade 3 and 4 
Table 3 Outcomes of patients treated with repeat breast conserving surgery and radiotherapy following ipsilateral breast tumor recurrence

\begin{tabular}{llllllll}
\hline Study/year & $\begin{array}{l}\text { Number of } \\
\text { patients }\end{array}$ & $\begin{array}{l}\text { Median follow-up } \\
\text { (months) }\end{array}$ & RT technique & $\begin{array}{l}\text { Repeat RT } \\
\text { dose (Gy) }\end{array}$ & $\begin{array}{l}\text { Grade 3/4 } \\
\text { toxicity (\%) }\end{array}$ & $\begin{array}{l}\text { Local control } \\
(\%)\end{array}$ & $\begin{array}{l}\text { Overall survival } \\
(\%)\end{array}$ \\
\hline Deutsch [40] 2002 & 39 & 51.5 & EBRT & 50 & NR & 77 & 78 \\
Kraus [41] 2007 & 15 & 26 & IORT & 20 & 0 & 100 & 93 \\
Chada [38] 2008 & 15 & 36 & BT & 30 or 45 & 0 & 89 & 100 \\
Guix [42] 2010 & 36 & 89 & BT & 30 & 0 & $89^{\mathrm{a}}$ & $97^{\mathrm{a}}$ \\
Kauer [37] 2012 & 39 & 57 & BT & 50 & $17^{\mathrm{b} / 0}$ & 93 & 87 \\
Hannoun [35] 2013 & 217 & 46.8 & BT & LDR 46 & 11 & $93^{\mathrm{a}}$ & $76^{\mathrm{a}}$ \\
& & & & PDR 50.4 & & &
\end{tabular}

NR not reported, $R T$ radiation therapy, EBRT external beam radiotherapy, IORT intraoperative radiotherapy, $L D R$ low dose rate, $P D R$ pulsed dose rate, $H D R$ high dose rate

${ }^{\mathrm{a}} 10$-year actuarial

${ }^{\mathrm{b}} 4 \%$ breast tissue fibrosis and $13 \%$ subjective breast pain

complication rates were $10 \%$ and $1 \%$ (ulceration), respectively. Excellent or good cosmetic results were achieved in $85 \%$. Further endpoints were the evaluation of survival rates without second IBTR, as well as metastatic recurrence, DFS, and OS. In comparison to salvage mastectomy series, results were reported to be at least equivalent, with 5- and 10 -year actuarial rates for metastatic recurrence of $9.6 \%$ and $19.1 \%$, DFS of $84.6 \%$ and $77.2 \%$, and OS of $88.7 \%$ and $76.4 \%$, respectively. Further single-institution studies with small patient numbers support these data [36-39].

\section{External beam radiotherapy after BCS for IBTR}

There is a single report on external beam radiotherapy (EBRT) for treatment of IBTR [40] comprising 39 patients. Retreatment was performed using electrons in single fractional doses of 2 Gy up to 50 Gy to the involved quadrant. At a median follow-up of 51.5 months, 30 women $(76.9 \%)$ had an intact breast free of tumor. The RTOG initiated a phase II study of repeat breast-preserving surgery and 3D conformal partial breast reirradiation (PBI) for local recurrence of breast carcinoma with single doses of $1.5 \mathrm{~Gy}$ in 15 fractions, twice daily, to a total dose of 45 Gy [22]. The study has reached the accrual goal of 61 patients and is closed, but not yet published.

\section{Intraoperative radiotherapy after BCS for IBTR}

There is only one publication considering intraoperative radiotherapy (IORT) for reirradiation of IBRT [41]. A total of 15 patients were treated by applying IORT with $50-\mathrm{kV}$ $\mathrm{X}$-rays in single dosages of 14.7-20 Gy (applicator surface). At a medium follow-up of 26 months (1-60 months), no local recurrences occurred.

\section{Toxicity assessment/cosmetic outcome of repeat irradiation for IBTR}

In all publications, acute toxicities of the respective method were reported to be low, while the most frequent late reaction pattern was fibrosis. Particularly when assessed by standardized scoring systems, grade 1-2 sequelae in terms of fibrosis, telangiectasia, and/or pain ranged between 44 and $79 \%[35,37,42]$. Severe late reactions, such as skin necrosis or ulceration, were hardly ever stated. In the GEC-ESTRO series of 217 patients [35], 141 patients (65\%) developed late effects: cutaneous and subcutaneous fibrosis (67\%), telangiectasia (16\%), hyperpigmentation (9\%), and ulceration (1\%). Grade 3 and 4 complications were reported in 10and $1 \%$, respectively. The cosmetic results were assessed in 109 patients $(50.2 \%)$ and rated excellent in $52(48 \%)$, good in $40(37 \%)$, fair in $14(13 \%)$, and poor in $2(2 \%)$ patients.

Conclusions of the DEGRO expert panel for the therapy of ipsilateral breast cancer recurrences

- Although mastectomy is regarded as the standard of care for patients with IBRT, in a subset of patients, PBI after second $\mathrm{BCS}$ is an appropriate alternative to mastectomy (Table 1).

- This approach yields high breast preservation rates and does not seem to compromise oncologic safety.

- If a second breast conservation is performed, additional irradiation should be mandatory, particularly in patients who have not received previous irradiation.

- In the case of reirradiation, the largest experience base to date exists for multicatheter BT.

- There is only limited information about the effectiveness of EBRT or IORT, which should be preferentially performed in clinical trials.

- Prospective studies are needed to clearly define selection criteria, long-term local control, and toxicity. 


\section{Treatment of local recurrence after mastectomy}

Statements of the German S3 Guidelines 2012 [13]: Statement recurrence 2: Local recurrence after mastectomy

- An isolated chest wall recurrence should be completely resected (R0).

\section{Statement recurrence 5: Radiotherapy after surgery for recurrence}

a. The indication for radiotherapy after recurrence surgery should be discussed and decided on an interdisciplinary basis. Postoperative irradiation can be applied if no previous irradiation was accomplished or in cases of incomplete resection (R1/R2).

b. In inoperable patients, palliative radiotherapy can be reasonable for systemic control.

\section{Definition and patterns of recurrence}

A locoregional breast cancer recurrence after mastectomy is defined as the appearance of tumor in the ipsilateral chest wall, or the axillary, internal mammary, or supraclavicular lymph nodes [8]. The Early Breast Cancer Trialists' Collaborative Group analysis revealed a 10 -year risk of an isolated locoregional recurrence as the first event after mastectomy of $20.3 \%$ for patients with 1-3 positive axillary lymph nodes, and of $32.1 \%$ for patients with $\geq 4$ positive nodes. The addition of radiotherapy significantly reduced the risk to 3.8 and $13 \%$, respectively $[2,49,50]$. In cohorts treated with modern systemic therapies, the total locoregional recurrence rate is substantially lower; however, the relative risk reduction after radiotherapy remains unchanged [51]. Katz et al. [52] reported on local recurrence patterns in a retrospective study of 1031 women treated in five prospective trials with mastectomy and adjuvant chemotherapy without radiation therapy. After a median follow-up of 116 months, the most common sites of isolated locoregional recurrences were the chest wall and the supraclavicular lymph nodes. There is evidence that a local recurrence per se is the strongest predictor for a further recurrence [9].

\section{Treatment of resectable recurrences in radiation-naive patients}

If no previous irradiation has been performed, optimal treatment consists of complete excision of gross disease followed by irradiation $[8,53]$. This approach improved local control $[54,55]$ and may have an effect on survival $[53,56]$. Skinner et al. [57] evaluated the effects of dose escalation on local control and survival in 159 patients with an isolated locoregional recurrence after mastectomy. Patients in the standard treatment group were treated to a dose of 50 Gy plus a boost of $10 \mathrm{~Gy}$, while the dose escalation group was treated to a dose of 54 Gy plus a 12-Gy boost. The authors observed a $77 \%$ locoregional control rate (LCR) and a $55 \%$ OS rate at 5 years for the entire group. OS and LCR were not significantly improved in the dose escalation group. In summary, patients with an isolated locoregional recurrence after mastectomy should undergo surgical resection. Postoperative radiation therapy to the chest wall is mandatory and regional nodal irradiation is strongly advised $[18,58]$. A standard dose of 50-50.4 Gy with 1.8-/2-Gy fractions should be applied. An additional boost dose of 10 Gy can be applied, particularly if risk factors are present. A further approach to enhance radiation effectiveness is the additional use of hyperthermia. This combination improved clinical response and local control in several phase II studies and randomized trials [59, 60].

For systemic management, endocrine therapy should be administered to all hormone receptor-positive patients in addition to local excision and radiotherapy [61]. In a prospective randomized study, Aebi and colleagues [62] investigated the effects of chemotherapy in 162 patients with completely resected isolated locoregional breast cancer recurrences. These authors found that adjuvant chemotherapy in addition to radiation and endocrine therapy prolonged DFS and OS, particularly in patients with estrogen receptornegative locoregional relapse. The 5-year DFS and OS rates were 69 and $88 \%$, respectively. This result challenges the current practice of reluctant use of chemotherapy and provides evidence in favor of offering adjuvant chemo- and radiotherapy to women with completely resected isolated locoregional relapse of breast cancer.

\section{Treatment of unresectable recurrences in radiation- naive patients}

In patients with unresectable isolated locoregional recurrences who have not previously been irradiated, radiation therapy is mandatory. In a retrospective study, Skinner et al. [57] reported that patients with gross disease at the time of radiation had significantly lower 5-year local control $(63 \%)$ and survival rates $(34 \%)$ compared to patients with no residual disease after surgery or systemic therapy (81 and $62 \%$, respectively). If complete remission after radiation therapy was accomplished, the 5-year survival rate increased from 27 to $62 \%$ [57]. Therefore, the same recommendations for radiation and endocrine therapy apply as for resectable disease. The boost dose can be increased depending on the size and location of the recurrence. The indication for additional chemotherapy should be defined on an individual basis, since no prospective data are available [63-65]. In summary, multimodality therapy including systemic and radiation therapy has the potential to cure selected patients [9, 53, 66-68]. 
Therapy of locoregional recurrences after mastectomy in previously irradiated patients

Treatment options are limited in patients with locoregional recurrences after mastectomy and adjuvant radiotherapy. The optimal sequence of multimodal treatments in this situation has not been evaluated in prospective trials. In current practice, most of these patients are initially treated with systemic therapy, in analogy to neoadjuvant systemic treatment of primarily unresectable breast cancer. If complete resection is possible, surgery should be accomplished; however, "heroic surgery" resulting in large tissue defects or prolonged wound healing problems should be avoided. Traditionally, reirradiation has been used with caution, in fear of an increased normal tissue complication rate. However, a number of small to intermediate size clinical trials have revealed that the grade IV late toxicity after reirradiation with EBRT was within an acceptable range, not exceeding $12 \%$ [5, 69-74]. Simultaneous radiochemotherapy as a treatment option has been investigated in a limited number of trials $[63,64]$.

\section{Reirradiation with or without regional hyperthermia}

Laramore et al. [69] reported on 13 patients treated with conventionally fractionated electrons for chest wall recurrences. All patients had received previous postoperative chest wall irradiation with doses between 40 and $50 \mathrm{~Gy}$. Of these patients, $62 \%$ were alive and free of local disease after a median follow-up of 12 months. Skin reactions were limited to temporary erythema and dry or moist desquama- tion. Harms et al. [75] reported on a retrospective study in 58 patients treated with PDR BT molds. The local control rate was $79 \%$. Grade III fibrosis was experienced by $10 \%$ of the patients and grade IV late effects were suffered by $7 \%$.

An increasing number of studies on the combination of hyperthermia and reirradiation of the chest wall have been published (Table 4; [59, 60, 71-74, 76, 77]). Jones and colleagues [60] enrolled 109 patients with superficial tumors (70 patients with breast cancer) in a prospective randomized trial comparing irradiation of chest wall recurrences with irradiation and additional hyperthermia. The complete response rate was $66.1 \%$ in the hyperthermia and $42.3 \%$ in the irradiation-only arm. Previously irradiated patients had the greatest incremental gain in complete response: $23.5 \%$ in the non-hyperthermia versus $68.2 \%$ in the hyperthermia arm. No OS benefit was seen. The authors concluded that adjuvant hyperthermia resulted in a significant local control benefit in patients with superficial tumors receiving radiation therapy. These data are supported by a meta-analysis of five randomized trials including 306 patients with advanced primary or recurrent breast cancer [59]. The complete remission rate was significantly improved in patients treated with combined radiation and hyperthermia compared to radiation alone (59 vs. $41 \%$ ). OS was not improved.

More recent data were published in a retrospective analysis of 198 patients who underwent either $\mathrm{R} 0(n=107)$ or $\mathrm{R} 1$ resection $(n=91)$ for recurrent breast cancer. Hyperthermia was used as an adjunct to reirradiation (eight 4-Gy fractions; [73]). After a median follow-up of 42 months, the 5-year locoregional control rate was $78 \%$. The 5 -year grade III/IV

Table 4 Outcomes of patients with locoregional chest wall recurrences treated with repeat irradiation $+/-$ hyperthermia

\begin{tabular}{|c|c|c|c|c|c|c|}
\hline Study & Patients $n=$ & Initial dose (Gy) & RT technique & Repeat dose (Gy) & Complete remission $(\%)$ & Toxicity grade $(\%)$ \\
\hline Delanian [79] & 11 & $45-65$ & $\mathrm{BT}$ & 60 & 81.8 & $\begin{array}{l}\text { II/III } 45 \\
\text { IV } 9\end{array}$ \\
\hline Harms [75] & 58 & $36-70$ & BT & $2 \times 20$ & 79.3 & $\begin{array}{l}\text { III } 60^{\mathrm{b}} \\
\text { IV } 7\end{array}$ \\
\hline Laramore [69] & 13 & $40-50$ & EBRT & $40-50$ & 61.5 & $\begin{array}{l}\text { III } 0 \\
\text { IV } 0\end{array}$ \\
\hline Phromratanapongse [71] & 44 & $35-66$ & $\mathrm{EBRT}+\mathrm{HT}$ & $16-56$ & 40.9 & $\begin{array}{l}\text { III } 25 \\
\text { IV NR }\end{array}$ \\
\hline Li [80] & 41 & 58 & EBRT & 43 & 56 & IV 8 \\
\hline Jones $^{\mathrm{a}}[60]$ & $\begin{array}{l}52 \\
56\end{array}$ & NR & $\begin{array}{l}\text { EBRT } \\
\text { EBRT + HT }\end{array}$ & $\begin{array}{l}30-66 \\
60-70\end{array}$ & $\begin{array}{l}42.3 \\
66.1\end{array}$ & $\begin{array}{l}\text { III } 2 \\
\text { III } 5\end{array}$ \\
\hline Kouloulias [81] & 15 & 60 & $\mathrm{EBRT}+\mathrm{HT}$ & 30.6 & 20 & $\begin{array}{l}\text { III NR } \\
\text { IV } 7\end{array}$ \\
\hline Linthorst [73] & 198 & 48 & $\mathrm{EBRT}+\mathrm{HT}$ & $8 \times 4$ & $78^{\mathrm{c}}$ & III/IV $11.9^{\mathrm{d}}$ \\
\hline Linthorst [78] & 248 & 49 & $\mathrm{EBRT}+\mathrm{HT}$ & $8 \times 4$ & $39^{c}$ & III $1^{\mathrm{d}}$ \\
\hline
\end{tabular}

$B T$ brachytherapy, $H T$ hyperthermia, $E B R T$ external beam radiotherapy, $N R$ not reported

${ }^{a}$ Breast cancer and other tumor entities

'Predominantly telangiectasia

'5-year local control rate

d5-year rate 
late toxicity rate amounted to $11.9 \%(n=15$ skin ulcerations, $n=5$ osteoradionecrosis of the ribs). The same working group investigated 248 patients with a macroscopic breast cancer recurrence treated with reirradiation and hyperthermia [78]. After a median follow-up period of 32 months, $70 \%$ of patients had a complete remission. The 5 -year local control rate was $39 \%$. Thermal burn was developed by $23 \%$ of patients, which healed with conservative measures. The incidence of 5 -year late grade 3 toxicity was $1 \%$.

Conclusions of the DEGRO expert panel for the therapy of locoregional recurrences after mastectomy

- Multimodality therapy including systemic therapy, surgery, and radiation $+/-$ hyperthermia achieves a high rate of local control and can be curative with long-term survival in a subset of patients.

- Patients with an isolated locoregional recurrence after mastectomy should undergo surgical resection. Postoperative radiation therapy to the chest wall is mandatory and regional nodal irradiation (RNI) is strongly advised.

- In radiation-naive patients, the chest wall and regional lymph nodes should be treated with doses of 50-50.4 Gy (1.8-2 Gy per day). A boost dose of 10 Gy may be applied. Further dose escalation does not seem to improve treatment results.

- In previously irradiated patients with a high risk of a second local recurrence after surgical resection or in patients with unresectable recurrences, reirradiation should be strongly considered. Indication and dose concepts depend on the time interval to first radiotherapy, presence of late radiation effects, and concurrent or sequential systemic treatment.

- In the absence of severe radiogenic stigmata and an appropriate time interval ( $>1$ year), reirradiation with doses between 45 and $50 \mathrm{~Gy}$ is recommended, but should not exceed cumulative doses of $100-110 \mathrm{~Gy}_{3}\left(2-\mathrm{Gy}_{3}\right.$ equivalent dose).

- Particularly in previously irradiated patients, combination with hyperthermia can further improve tumor control.

\section{Regional recurrences and isolated supraclavicular lymph node recurrences}

\section{Statement of the German S3 Guidelines 2012 [13]:} Statement recurrence 3: Isolated regional recurrence

a. In case of an isolated regional recurrence, local control should be achieved with surgery/radiotherapy.

\section{Axillary recurrence}

The reported cumulative risk of axillary recurrence after axillary dissection ranges from 0.5 to $3.0 \%[82,83]$. Voogd et al. [82] investigated the long-term prognosis of 59 out of 4669 patients $(1.3 \%)$ with an axillary recurrence after axillary dissection. The median interval between treatment of the primary tumor and diagnosis of axillary recurrence was 2.6 years (range $0.3-10.7$ years). Distant metastases occurred in 38 of the 59 patients. The 5- and 10-year distant recurrence-free survival rates were $39 \%$ (95\% confidence interval, CI: $25-52 \%)$ and $29 \%$ (95\% CI: $16-42 \%)$, respectively. The authors concluded that axillary recurrence following axillary dissection was associated with a high rate of subsequent distant metastasis and poor overall prognosis, although cure was still achievable in one third of the patients. Newman and colleagues [84] reported on 44 out of 4255 (1\%) breast cancer patients with axillary recurrence. With a median follow-up of 70.8 months, complete control of axillary recurrence was achieved in 31 patients $(71 \%)$. Distant metastases developed in $50 \%$ and were more likely to occur in the case of uncontrolled axillary recurrences. Of the patients receiving multimodality therapy $(75 \%)$, the most common sequence was surgery followed by either systemic therapy and/or nodal irradiation. The addition of radiotherapy significantly improved axillary disease control (80.8 vs. $55.6 \%)$.

\section{Isolated supraclavicular lymph node recurrence}

Van der Sangen et al. [85] investigated 4669 patients treated for invasive breast cancer. An isolated supraclavicular lymph node recurrence developed in 42 patients $(0.9 \%)$. Different treatments, including surgery, radiotherapy, systemic therapy, or a combination of these, were applied. Complete remission was achieved in 35 patients (83\%). However, a second supraclavicular recurrence occurred in a third of these patients. Overall, 6 patients (14\%) were alive without evidence of disease after a follow-up period of 4.4-8.3 years. The 5-year actuarial OS and distant diseasefree survival rates were 38 and $22 \%$, respectively. Distant disease-free survival was somewhat better in the 25 patients who underwent radiotherapy as part of the treatment for supraclavicular recurrence than it was in the 17 patients who did not $(p=0.06)$. The difference reached statistical significance after the exclusion of 8 patients who had received axillary and supraclavicular radiotherapy as part of their primary tumor treatment $(p=0.002)$. In summary, complete remission can be obtained in most patients with isolated supraclavicular recurrence, although the prognosis for these patients is poor. 
Conclusions of the DEGRO expert panel for the treatment of axillary or supraclavicular lymph node recurrence

- Isolated axillary and supraclavicular recurrences from breast cancer are uncommon and may follow any stage of disease. Of the affected patients, $50-65 \%$ develop distant metastases.

- To date, only retrospective data concerning the treatment of regional nodal recurrence are available.

- Durable disease control is best achieved with multimodality therapy including surgery and radiotherapy. Approximately one third of patients with an axillary breast cancer recurrence can be cured with multimodal therapy.

- Radiation therapy significantly improves local control and should be applied whenever feasible.

\section{Compliance with ethical guidelines}

Conflict of interest W. Harms, W. Budach, J. Dunst, P. Feyer, R. Fietkau, W. Haase, D. Krug, M.D. Piroth, M.-L. Sautter-Bihl, F. Sedlmayer, R. Souchon, F. Wenz, and R. Sauer state that there are no conflicts of interest.

The accompanying manuscript does not include studies on humans or animals.

Open Access This article is distributed under the terms of the Creative Commons Attribution License which permits any use, distribution, and reproduction in any medium, provided the original author(s) and the source are credited.

\section{References}

1. Early Breast Cancer Trialists' Collaborative Group (EBCTCG) (2011) Effect of radiotherapy after breast-conserving surgery on 10 -year recurrence and 15-year breast cancer death: meta-analysis of individual patient data for 10,801 women in 17 randomised trials. Lancet 378:1707-1716

2. Early Breast Cancer Trialists' Collaborative Group (EBCTCG) (2014) Effect of radiotherapy after mastectomy and axillary surgery on 10-year recurrence and 20-year breast cancer mortality: meta-analysis of individual patient data for 8135 women in 22 randomised trials. Lancet 383:2127-2135

3. Christiansen P, Al Suliman N, Bjerre K, Moller S (2008) Recurrence pattern and prognosis in low-risk breast cancer patients-data from the DBCG 89-A programme. Acta Oncol 47:691-703

4. Bartelink H, Maingon P, Poortmans P et al (2015) Whole-breast irradiation with or without a boost for patients treated with breastconserving surgery for early breast cancer: 20 -year follow-up of a randomised phase 3 trial. Lancet Oncol 16:47-56

5. Wahl AO, Rademaker A, Kiel K et al (2008) Multi-institutional review of repeat irradiation of chest wall and breast for recurrent breast cancer. Int J Radiat Oncol Biol Phys 70:477-484

6. Nielsen HM, Overgaard M, Grau C et al (2006) Study of failure pattern among high-risk breast cancer patients with or without postmastectomy radiotherapy in addition to adjuvant systemic therapy: long term results from the Danish Breast Cancer Co-operative Group DBCG 82b and c randomized studies. J Clin Oncol 24:2268-2275
7. Fourquet A, Campana F, Zafrani B et al (1989) Prognostic factors of breast recurrence in the conservative management of early breast cancer: a 25-year follow-up. Int J Radiat Oncol Biol Phys 17:719-725

8. Bedwinek J (1994) Natural history and management of isolated local-regional recurrence following mastectomy. Semin Radiat Oncol 4:260-269

9. van Tienhoven G, Voogd AC, Peterse JL et al (1999) Prognosis after treatment for loco-regional recurrence after mastectomy or breast conserving therapy in two randomised trials (EORTC 10801 and DBCG-82TM). EORTC Breast Cancer Cooperative Group and the Danish Breast Cancer Cooperative Group. Eur J Cancer 35:32-38

10. Sedlmayer F, Sautter-Bihl ML, Budach W et al (2013) DEGRO practical guidelines: radiotherapy of breast cancer I: radiotherapy following breast conserving therapy for invasive breast cancer. Breast Cancer Expert Panel of the German Society of Radiation Oncology (DEGRO). Strahlenther Onkol 189:825-833

11. Wenz F, Sperk E, Budach W, Breast Cancer Expert Panel of the German Society of Radiation Oncology (DEGRO) et al (2014) DEGRO practical guidelines for radiotherapy of breast cancer IV: radiotherapy following mastectomy for invasive breast cancer. Strahlenther Onkol 190:705-714

12. Budach W, Matuschek C, Bölke E et al (2015) DEGRO practical guidelines for radiotherapy of breast cancer $\mathrm{V}$ : therapy for locally advanced and inflammatory breast cancer, as well as local therapy in cases with synchronous distant metastases. Strahlenther Onkol 191:623-633

13. Interdisziplinäre S3-Leitlinie für die Diagnostik, Therapie und Nachsorge des Mammakarzinoms. Langversion 3.0, Aktualisierung 2012. www.leitlinienprogramm-onkologie.de

14. Fisher B, Anderson S, Bryant J et al (2002) Twenty year follow up of a randomized trial comparing total mastectomy, lumpectomy, and lumpectomy plus irradiation for the treatment of invasive breast cancer. N Engl J Med 347:1233-1241

15. Wapnir IL, Anderson SJ, Mamounas EP et al (2006) Prognosis after ipsilateral breast tumor recurrence and locoregional recurrences in five National Surgical Adjuvant Breast and Bowel Project nodepositive adjuvant breast cancer trials. J Clin Oncol 24:2028-2037

16. Bouganim M, Tsetkova E, Clemons M et al (2013) Evolution of sites of recurrence after early breast cancer over the last 20 years: implications for patient care and future research. Breast Cancer Res Treat 139:603-606

17. Fastner G, Hauser-Kronberger C, Moder A et al (2015) Survival and local control rates of triple-negative breast cancer patients treated with boost-IOERT during breast-conserving surgery. Strahlenther Onkol. (Epub ahead of print)

18. NCCN Clinical Practice Guidelines in Oncology (NCCN Guidelines $^{\circledR}$ ), Breast Cancer, Version 3.2015 NCCN.org

19. Anderson SJ, Wapnir I, Dignam JJ (2009) Prognosis after ipsilateral breast tumor recurrence and locoregional recurrences in patients treated by breast conserving therapy in five national surgical adjuvant breast and bowel project protocols of node-negative breast cancer. J Clin Oncol 27:2466-2473

20. Fowble B, Solin LJ, Schultz DJ et al (1990) Breast recurrence following conservative surgery and radiation: patterns of failure, prognosis, and pathologic findings from mastectomy specimens with implications for treatment. Int $\mathrm{J}$ Radiat Oncol Biol Phys 19:833-842

21. Vila J, Garcia-Etienne CA, Vavassori A, Gentilini O (2014) Conservative surgery for ipsilateral breast tumor recurrence. J Surg Oncol 110:62-67

22. RTOG 1014; Radiation therapy in treating women with locally recurrent breast cancer previously treated with repeat breast preserving surgery. http://clinicaltrials.gov/ct2/show/NTC01082211?term 1/4RTOGp1014\&rank1/41 
23. Sautter-Bihl ML, Sedlmayer F, Budach W et al (2012) When are breast cancer patients old enough for the quitclaim of local control? Strahlenther Onkol 188:1069-1073

24. Veronesi U, Marubini E, Del Vecchio M et al (1995) Local recurrences and distant metastases after conservative breast cancer treatments: partly independent events. J Natl Cancer Inst 87:19-27

25. Gujral DM, Sumo G, Owen JR et al (2011) Ipsilateral breast tumor relapse: local recurrence versus new primary tumor and the effect of whole breast radiotherapy on the rate of new primaries. Int $\mathbf{J}$ Radiat Oncol Biol Phys 79:19-25

26. Smith TE, Lee D, Turner BC et al (2000) True recurrence vs. new primary ipsilateral breast tumor relapse: an analysis of clinical and pathologic differences and their implications in natural history, prognoses, and therapeutic management. Int J Radiat Oncol Biol Phys 48:1281-1289

27. Komoike Y, Akiyama F, Iino Y et al (2005) Analysis of ipsilateral breast tumor recurrences after breast-conserving treatment based on the classification of true recurrences and new primary tumors. Breast Cancer 12:104-111

28. Huang E, Buchholz TA, Meric F et al (2002) Classifying local disease recurrences after breast conservation therapy based on location and histology: new primary tumors have more favorable outcomes than true local disease recurrences. Cancer 95:2059-2067

29. Nishimura S, Takahashi K, Akiyama F et al (2005) Classification of ipsilateral breast tumor recurrence after breast-conserving therapy: new primary cancer allows a good prognosis. Breast Cancer $12: 112-117$

30. Fodor J, Major T, Polgár C et al (2008) Prognosis of patients with local recurrence after mastectomy or conservative surgery for early stage invasive breast cancer. Breast 17:302-308

31. van Laar C, van der Sangen MJ, Poortmans PM et al (2013) Local recurrence following breast-conserving treatment in women aged 40years or younger: trends in risk and the impact on prognosis in a population-based cohort of 1143 patients. Eur J Cancer 49:3093-3101

32. Miles RC, Gullerud RE, Lohse CM et al (2012) Local recurrence after breast-conserving surgery: multivariable analysis of risk factors and the impact of young age. Ann Surg Oncol 19:1153-1159

33. Alpert TE, Kuerer HM, Arthur DW et al (2005) Ipsilateral breast tumor recurrence after breast conservation therapy: outcomes of salvage mastectomy vs. salvage breast-conserving surgery and prognostic factors for salvage breast preservation. Int $\mathrm{J}$ Radiat Oncol Biol Phys 63:845-851

34. Sedlmayer F, Zehentmayr F, Fastner G (2013) Partial breast reirradiation for local recurrence of breast carcinoma: benefit and long term side effects. Breast 22:141-146

35. Hannoun-Levi JM, Resch A, Gal J et al (2013) Accelerated partial breast irradiation with interstitial brachytherapy as second conservative treatment for ipsilateral breast tumour recurrence: multicentric study of the GEC-ESTRO Breast Cancer Working Group. Radiother Oncol 108:226-231

36. Resch A, Fellner C, Mock U et al (2002) Locally recurrent breast cancer: pulse dose rate brachytherapy for repeat irradiation following lumpectomy-a second chance to preserve the breast. Radiology 225:713-718

37. Kauer-Dorner D, Pötter R, Resch A et al (2012) Partial breast irradiation for locally recurrent breast cancer within a second breast conserving treatment: alternative to mastectomy? Results from a prospective trial. Radiother Oncol 102:96-101

38. Chadha M, Feldman S, Boolbol S et al (2008) The feasibility of a second lumpectomy and breast brachytherapy for localized cancer in a breast previously treated with lumpectomy and radiation therapy for breast cancer. Brachytherapy 7:22-28
39. Trombetta M, Julian T, Bhandari T et al (2008) Breast conservation surgery and interstitial brachytherapy in the management of locally recurrent carcinoma of the breast: the Allegheny General Hospital experience. Brachytherapy 7:29-36

40. Deutsch M (2002) Repeat high-dose external beam irradiation for in-breast tumor recurrence after previous lumpectomy and whole breast irradiation. Int J Radiat Oncol Biol Phys 53:687-691

41. Kraus-Tiefenbacher U, Bauer L, Scheda A et al (2007) Intraoperative radiotherapy (IORT) is an option for patients with localized breast recurrences after previous external-beam radiotherapy. BMC Cancer 7:178

42. Guix B, Lejárcegui JA, Tello JI et al (2010) Exeresis and brachytherapy as salvage treatment for local recurrence after conservative treatment for breast cancer: results of a ten-year pilot study. Int J Radiat Oncol Biol Phys 78:804-810

43. Kurtz JM, Jacquemier J, Torhorst J et al (1989) Conservation therapy for breast cancers other than infiltrating ductal carcinoma. Cancer 63:1630-1635

44. Abner AL, Recht A, Eberlein T et al (1993) Prognosis following salvage mastectomy for recurrence in the breast after conservative surgery and radiation therapy for early-stage breast cancer. J Clin Oncol 11:44-48

45. Salvadori B, Marubini E, Miceli R et al (1999) Reoperation for locally recurrent breast cancer in patients previously treated with conservative surgery. Br J Surg 86:84-87

46. Voogd AC, van Tienhoven G, Peterse HL et al (1999) Local recurrence after breast conservation therapy for early stage breast carcinoma: detection, treatment, and outcome in 266 patients. Dutch study group on Local Recurrence after Breast Conservation (BORST). Cancer 85:437-446

47. Ishitobi M, Komoike Y, Nakahara S et al (2011) Repeat lumpectomy for ipsilateral breast tumor recurrence after breast-conserving treatment. Oncology 81:5381-5366

48. Gentilini O, Botteri E, Veronesi P et al (2012) Repeating conservative surgery after ipsilateral breast tumor reappearance: criteria for selecting the best candidates. Ann Surg Oncol 19:3771-3776

49. Sautter-Bihl ML, Sedlmayer F, Budach W, Breast Cancer Expert Panel of the German Society of Radiation Oncology (DEGRO) et al (2014) DEGRO practical guidelines: radiotherapy of breast cancer III-radiotherapy of the lymphatic pathways. Strahlenther Onkol 190:342-351

50. Sautter-Bihl ML, Sedlmayer F, Budach W, Breast Cancer Expert Panel of the German Society of Radiation Oncology (DEGRO) et al (2014) How nescience may obscure evidence. Strahlenther Onkol 190:861-863

51. Tendulkar RD, Rehman S, Shukla ME et al (2012) Impact of postmastectomy radiation on locoregional recurrence in breast cancer patients with 1-3 positive lymph nodes treated with modern systemic therapy. Int J Radiat Oncol Biol Phys 83:577-581

52. Katz A, Strom EA, Buchholz TA et al (2000) Locoregional recurrence patterns after mastectomy and doxorubicin-based chemotherapy: implications for postoperative irradiation. J Clin Oncol 18:2817-2827

53. Schwaibold F, Fowble BL, Solin LJ et al (1991) The results of radiation therapy for isolated local regional recurrence after mastectomy. Int J Radiat Oncol Biol Phys 21:299-310

54. Stadler B, Kogelnik H (1987) Local control and outcome of patients irradiated for isolated chest wall recurrences of breast cancer. Radiother Oncol 8:105-111

55. Halverson K, Perez C, Kuske R et al (1990) Isolated local-regional recurrence of breast cancer following mastectomy: radiotherapeutic management. Int J Radiat Oncol Biol Phys 19:851-858

56. Beck T, Hart N, Woodart D (1983) Local or regionally recurrent carcinoma of the breast: results of therapy in 121 patients. J Clin Oncol 1:400-405 
57. Skinner HD, Strom EA, Motwani SB et al (2013) Radiation dose escalation for loco-regional recurrence of breast cancer after mastectomy. Radiat Oncol 8:13

58. Ishitobi M, Matsushita A, Nakayama T et al (2014) Regional lymphatic recurrence after salvage surgery for ipsilateral breast tumor recurrence of breast cancer without local treatment for regional lymphatic basin. J Surg Oncol 110:265-269

59. Vernon CC, Hand JW, Field SB et al (1996) Radiotherapy with or without hyperthermia in the treatment of superficial localized breast cancer: results from five randomized controlled trials-International Collaborative Hyperthermia Group. Int J Radiat Oncol Biol Phys 35:731-744

60. Jones EL, Oleson JR, Prosnitz LR et al (2005) Randomized trial of hyperthermia and radiation for superficial tumors. J Clin Oncol 23:3079-3085

61. Borner M, Bacchi M, Goldhirsch A et al (1994) First isolated locoregional recurrence following mastectomy for breast cancer: results of a phase III multicenter trial comparing systemic treatment with observation after excision and radiation. J Clin Oncol 12:2071-2077

62. Aebi S, Gelber S, Anderson SJ (2014) Chemotherapy for Isolated Locoregional Recurrence of Breast Cancer: the CALOR Randomised Trial. Lancet Oncol 15:156-163

63. Karasawa K, Katsui K, Seki K et al (2003) Radiotherapy with concurrent docetaxel for advanced and recurrent breast cancer. Breast Cancer 10:268-274

64. Semrau S, Gerber B, Reimer T et al (2006) Concurrent radiotherapy and taxane chemotherapy in patients with locoregional recurrence of breast cancer. A retrospective analysis. Strahlenther Onkol 182:596-603

65. Zagar TM, Higgins KA, Miles EF et al (2010) Durable palliation of breast cancer chest wall recurrence with radiation therapy, hyperthermia, and chemotherapy. Radiother Oncol 97:535-540

66. Ballo MT, Strom EA, Prost H et al (1999) Local-regional control of recurrent breast carcinoma after mastectomy: does hyperfractionated accelerated radiotherapy improve local control? Int J Radiat Oncol Biol Phys 44:105-112

67. Willner J, Kiricuta IC, Kölbl O (1997) Locoregional recurrence of breast cancer following mastectomy: always a fatal event? Results of univariate and multivariate analysis. Int J Radiat Oncol Biol Phys 37:853-863

68. Chagpar A, Kuerer HM, Hunt KK et al (2003) Outcome of treatment for breast cancer patients with chest wall recurrence according to initial stage: implications for post-mastectomy radiation therapy. Int J Radiat Oncol Biol Phys 57:128-135

69. Laramore GE, Griffin TW, Parker RG, Gerdes AJ (1978) The use of electron beams in treating local recurrence of breast cancer in previously irradiated fields. Cancer 41:991-995

70. Elkort RJ, Kelly W, Mozden PJ, Feldman MI (1980) A combined treatment program for the management of locally recurrent breast cancer following chest wall irradiation. Cancer 46:647-653

71. Phromratanapongse P, Steeves RA, Severson SB, Paliwal BR (1991) Hyperthermia and irradiation for locally recurrent previously irradiated breast cancer. Strahlenther Onkol 167:93-97
72. Van der Zee J, van der Holt B, Rietveld PJM et al (1999) Reirradiation combined with hyperthermia in recurrent breast cancer is a worthwhile local palliation. Br J Cancer 79:483-490

73. Linthorst M, van Geel AN, Baaijens M et al (2013) Re-irradiation and hyperthermia after surgery for recurrent breast cancer. Radiother Oncol 109:188-193

74. Linthorst M, van Geel AN, Baartman EA et al (2013) Effect of a combined surgery, re-irradiation and hyperthermia therapy on local control rate in radio-induced angiosarcoma of the chest wall. Strahlenther Onkol 189:387-393

75. Harms W, Krempien R, Hensley FW et al (2001) Results of chest wall re-irradiation using pulsed dose rate (PDR) brachytherapy moulds for breast cancer local recurrences. Int J Radiat Oncol Biol Phys 49:205-210

76. Amicheti M, Valdagni R, Graiff C, Valentini A (1991) Local-regional recurrences of breast cancer: treatment with radiation therapy and local microwave hyperthermia. Am J Clin Oncol 14:60-65

77. Kapp DS, Cox RC (1995) Thermal treatment parameters are most predictive of outcome in patients with single tumor nodules per treatment field in recurrent adenocarcinoma of the breast. Int J Radiat Oncol Biol Phys 33:887-899

78. Linthorst M, Baaijens M, Wiggenraad R et al (2015) Local control rate after the combination of re-irradiation and hyperthermia for irresectable recurrent breast cancer: Results in 248 patients. Radiother Oncol 117:217-222

79. Delanian S, Housset M, Brunel P et al (1992) Iridium 192 plesiocurietherapy using silicone elastomer plates for extensive locally recurrent breast cancer following chest wall irradiation. Int J Radiat Oncol Biol Phys 22:1099-1104

80. Li G, Mitsumori M, Ogura M et al (2004) Local hyperthermia combined with external irradiation for regional recurrent breast carcinoma. Int J Clin Oncol 9:179-183

81. Kouloulias VE, Dardoufas CE, Kouvaris JR et al (2002) Liposomal Doxorubicin in conjunction with re-irradiation and local hyperthermia treatment in recurrent breast cancer: a phase I/II trial. Clin Cancer Res 8:374-382

82. Voogd AC, Cranenbroek S, de Boer R et al (2005) MJC Long-term prognosis of patients with axillary recurrence after axillary dissection for invasive breast cancer. Eur J Surg Oncol 31:485-489

83. Harris EE, Hwang WT, Seyednejad F, Solin LJ (2003) Prognosis after regional lymph node recurrence in patients with stage I-II breast carcinoma treated with breast conservation therapy. Cancer 98:2144-2151

84. Newman LA, Hunt KK, Buchholz T et al (2000) Presentation, management and outcome of axillary recurrence from breast cancer. Am J Surg 180:252-256

85. Van der Sangen MJC, Coebergh JWW, Roumen RMH et al (2003) Detection, treatment, and outcome of isolated supraclavicular recurrence in 42 patients with invasive breast carcinoma. Cancer 98:11-17 